\title{
The road map to better hospitals
}

A

"road map" for improved performance should emerge from the Canadian Institute for Health Information's (CIHI) new Webbased benchmarking tool for the nation's 600 hospitals, health experts, politicians and policy-makers say.

But the tool's usefulness will ultimately depend on the ability of health administrators to interpret findings and their willingness to ask for help or directions when it's clear they're on the wrong track.

The online resource, part of the Canadian Institute for Health Information's (CIHI) Canadian Hospital Reporting Project, provides four years of data across a series of 21 clinical indicators and nine financial indicators to compare the performance of large community, teaching and small hospitals (www.cihi .ca/CIHI-ext-portal/internet/en/document full/health+system+performance/indic ators/performance/indicator_ent).

It's an "absolutely necessary" step toward "real productive change around better outcomes," says Pamela Fralick, president and CEO of the Canadian Healthcare Association, the voice of the nation's hospitals.

But it's only a first step, Fralick stresses. "We can start comparing ourselves, but how do we figure out what to do [with the results of that comparison]? And those hospitals that have made more progress than others - what did they do to get there? This particular data source isn't going to answer those questions, nor is it intended to, but it's going to bring them up to the surface."

CIHI's online resource is "the starting point for that type of analysis," Fralick adds. But the "next step is to look at initiatives [to share best practices and test strategies for quality improvement] that will use this data as a jumping off point."

Provincial governments will certainly find it useful, Alberta Health and Wellness Minister Fred Horne says, noting that comparative data generated by the benchmarking tool confirmed

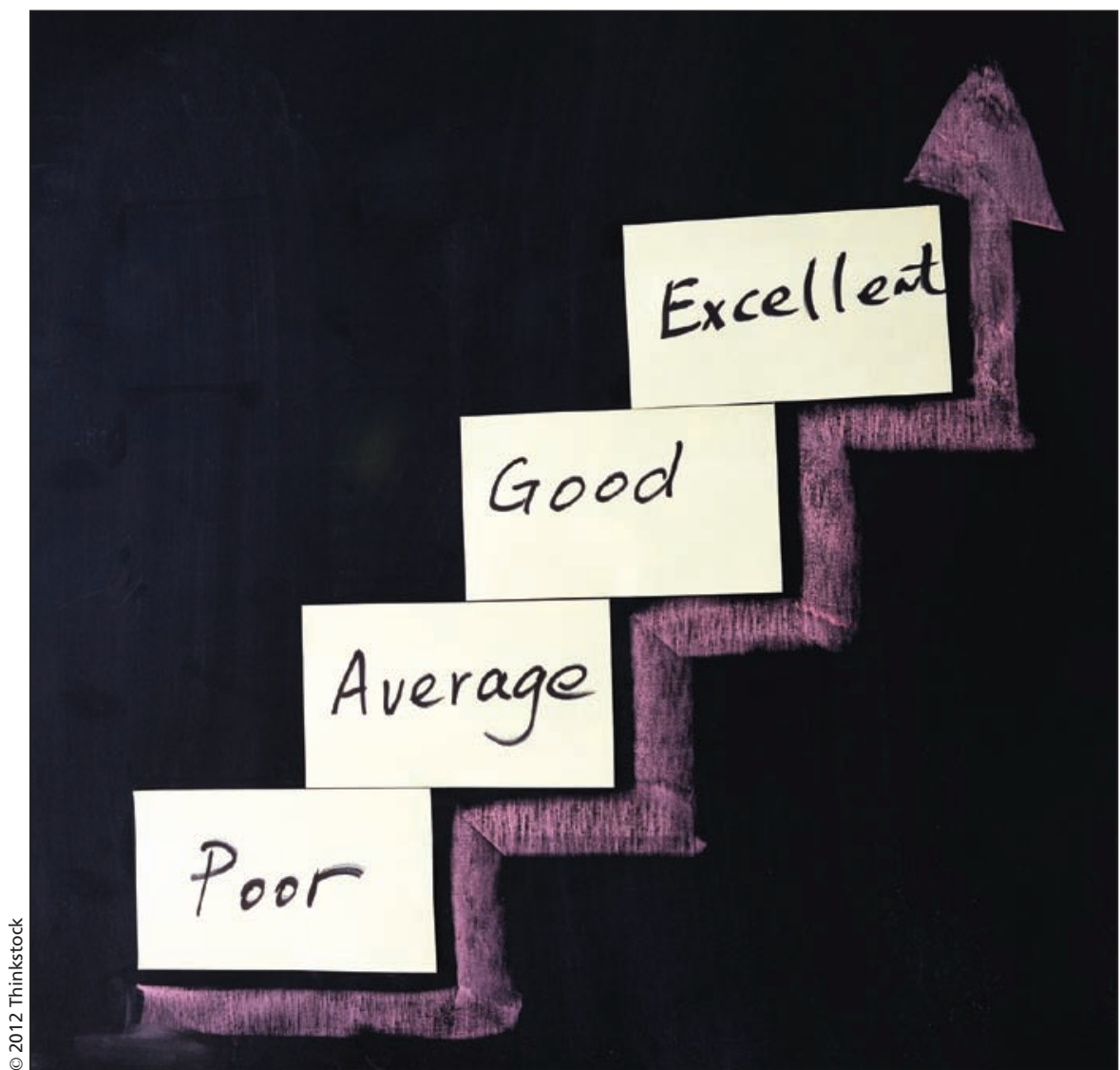

The value of a new benchmarking tool for hospitals lies in its ability to readily identify facilities, and aspects of health care, that need improvement, experts say.

the success of several recent provincial strategies. "We were leading the country in terms of [having the lowest] administrative costs as compared to patient care costs. We've got through some major changes here in the last few years and it appears we're becoming more efficient."

The province has consolidated "a lot of the back office" administrative functions since dissolving its regional health authority system in the last few years, Horne explains. "For example, we used to have seven payroll systems. Now, we have one. We've achieved about $\$ 700$ million in savings just from consolidating some of those corporate services and been able to reinvest that in patient care."

In fiscal 2009/10, Alberta reported the lowest administration costs as a per- centage of total health care costs at $3.5 \%$, while Ontario had the highest at $5.9 \%$ (www.cmaj.ca/lookup/doi/10.1503 /cmaj.109-4178).

"When we see results like this, it tells us we're on the right track," Horne says. "As we use this tool, we'll be able to go beyond the comparisons to delve into some of the specific strategies that are used in different parts of the country and look at what application they may have in our province."

Others say the tool's value lies in readily identifying facilities, and aspects of health care, that need improvement.

Although Saskatchewan had already identified lowering readmission rates as one such area, the benchmarking tool has been a "helpful trigger to get us looking at not only what happens within the hospital ... but also how we support 
patients in the community," says Deb Jordan, executive director of acute and emergency services the Government of Saskatchewan - Health Department.

The tool is a particular boon to smaller provinces where "large teaching sites that provide highly specialized services are very small in number," and hospitals of any size may lack local peers, Jordan adds. "In times past, the focus [of comparison exercises] has tended to be on the very larger, highly-specialized services, and for good reason in terms of the numbers of patients seen and the costs of the services provided. But I think it's equally important for our smaller organizations and sites to be able to be actively engaged in quality improvement and this gives them good tools to be able to identify their peers across the country."

The identification of targets for quality improvement will also be the goal in
British Columbia, the province's Ministry of Health writes in a statement to CMAJ. "This public information will allow everyone to see how facilities are improving over time, or where they need to improve, which is good for the transparency and accountability of our publicly-funded health care system." Lauren Vogel, CMAJ

CMAJ 2012. DOI:10.1503/cmaj.109-4179 